\title{
EVALUATION OF FUNCTIONAL INSOLES FOR PROTECTIVE FOOTWEAR UNDER SIMULATED USE CONDITIONS
}

\author{
Emilia Irzmańska ${ }^{1, \star}$, Katarzyna Majchrzycka ${ }^{1}$, Izabella Krucińska², Michał Puchalski², Agnieszka Brochocka ${ }^{1}$, \\ Agnieszka Adamus-Włodarczyk ${ }^{1}$ \\ 1 Department of Personal Protective Equipment, Central Institute for Labour Protection - National Research Institute, ul. Wierzbowa 48, \\ 90-133 Łódź, Poland \\ 2 Lodz University of Technology, Institute of Material Science of Textiles and Polymer Composites, Centre of Advanced Technologies of Human-Friendly \\ Textiles 'Pro Humano tex', ul. Żeromskiego 116, 90-924 Łódź, Poland \\ *Corresponding author. E-mail: emirz@ciop.lodz.pl
}

\begin{abstract}
:
The objective of the work was to study the properties of functional insoles for protective footwear using an original methodology by simulating the dynamic real-life conditions. Two insole variants were examined; both are made from a three-layer composite with the middle layer being a polypropylene melt-blown nonwoven. The variants differed in terms of the presence or absence of a superabsorbent polymer (SAP) and a biocide in the middle layer. Insole samples were subjected to pressure and examined in terms of the adsorption and desorption of acidic and alkaline liquids, followed by tear strength experiments. In addition, the insoles were placed in protective footwear and the microclimate existing inside the resulting system was determined using T/RH sensors by means of three complementary methods: under controlled climatic conditions, on a thermal foot model, and on human subjects. The results clearly indicate that insoles containing SAP are more effective than those without SAP in terms of both hygienic and mechanical properties.
\end{abstract}

\section{Keywords:}

Protective footwear, insoles, hygienic properties, mechanical properties, textile structures

\section{Introduction}

In addition to its essential protective functions, personal protective equipment (PPE) should exhibit good hygienic properties [1]. This is particularly important for protective footwear because its constituent materials prevent effective distribution of the large amounts of heat and sweat produced by the feet during physical work. According to [2], the average amount of sweat produced by the human foot is approx. 2.5$3.0 \mathrm{~g} / \mathrm{h}$ at rest, $7.2 \mathrm{~g} / \mathrm{h}$ during ambulation, and $15.0 \mathrm{~g} / \mathrm{h}$ during strenuous work.

The hygienic requirements are governed by the Regulation (EU) 2016/425 of the European Parliament and of the Council, which stipulates that PPE enclosing the parts of the body to be protected (e.g., safety footwear) must be either designed in such a way as to minimize the perspiration resulting from use or equipped with a mechanism for absorbing perspiration [3].

These issues are consistent with the current trends prevalent in the development of innovative PPE. Particularly, the European development strategy sets out guidelines in terms of developing support textiles such as insoles, liners, and socks with antifungal and antibacterial properties, which should be vapor permeable (which is particularly important in the case of impermeable safety footwear) and characterized by a short service life (which could be beneficial for users with excessively sweating feet) [4].
Thus, efforts should be directed at improving the hygienic comfort of protective footwear users by designing and promoting replaceable sweat-absorbing components such as functional insoles $[5,6]$.

In testing the protective and hygienic parameters of functional insoles for protective footwear, methodology is of the essence. Currently, studies concerning the hygienic comfort of safety footwear can be divided into instrumental tests of individual footwear materials, trials involving human volunteers under controlled climate conditions, simulations involving thermal foot models, and questionnaire surveys [7-11]. The hygienic properties of footwear materials are usually assessed by standard methods including tests for water and vapor permeability, sorption properties, and thermal conductivity [12-15].

The objective of this work was to evaluate functional insoles for protective footwear using an original methodology by simulating the absorption and desorption under dynamic conditions of footwear use. Insole samples were subjected to pressure and examined in terms of the adsorption and desorption of acidic and alkaline liquids, followed by tear strength tests. Apart from that, the insoles were placed in protective footwear and the microclimate inside the resulting system was determined using $\mathrm{T} / \mathrm{RH}$ sensors using three complementary methods: under controlled climatic conditions, on a thermal foot model, and on human subjects. It should be noted that this is the first study to 
encompass such a wide array of functional tests of insoles for protective footwear.

The study material consisted of insoles with nonwovens developed by the present authors in their previous investigations and were used in conjunction with impermeable protective footwear $[16,17]$.

\section{Study material}

\subsection{Insoles}

The insoles were made from a composite consisting of three layers that were spot-welded using ultrasound. The composite was optimized by spot-welding to obtain an appropriate bonding strength between the layers while ensuring sufficient elasticity as compared to adhesive-bonded composites [18]. The three layers of the tested insoles were as follows (Figure 1):

1. upper layer in contact with the foot made of a polyester knitted spacer fabric;

2. middle layer made of a polypropylene melt-blown nonwoven with or without a superabsorbent polymer (SAP) and a biocide;

3. bottom layer in contact with the footwear sole made of a polypropylene reinforcing nonwoven.

The study involved two composite variants: reference insoles (variant I) and modified insoles (variant II) with middle nonwoven layer containing SAP and a biocide. The insoles were tested in conjunction with knee-high all-rubber safety footwear and reference socks made of cotton and polyamide (70/30\%) in simulation studies. Prior to tests, the insoles, socks, and footwear were conditioned at a temperature of $23 \pm 2^{\circ} \mathrm{C}$ and a relative humidity of $50 \pm 5 \%$ for $72 \mathrm{~h}$.
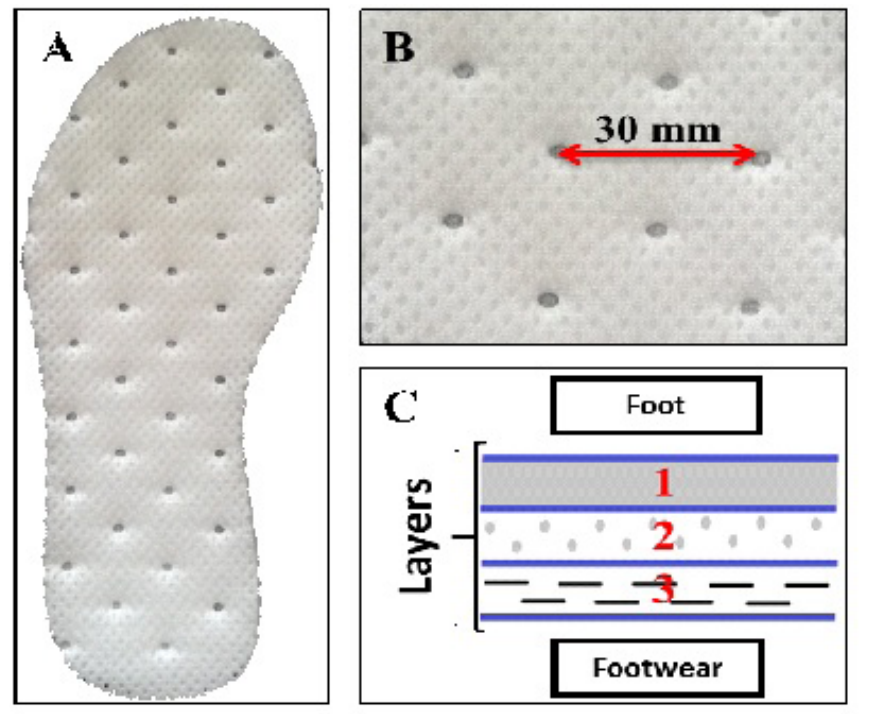

Figure 1. (A) Top view of the insole; (B) spot-weld distribution; (C) composite structure; 1 - upper layer in contact with the foot; 2 - middle layer made of modified nonwoven; 3 - bottom layer in contact with the footwear sole
Table 1. Characteristics of inserts used in the tests

\begin{tabular}{|c|c|c|c|}
\hline Variants & Size & Weight $(\mathbf{g})$ & Length (cm) \\
\hline \multirow{3}{*}{ I } & 42 & 8.58 & 26.0 \\
\cline { 2 - 4 } & 43 & 9.17 & 26.7 \\
\hline \multirow{2}{*}{ II } & 42 & 7.87 & 26.0 \\
\cline { 2 - 4 } & 43 & 8.34 & 26.7 \\
\hline
\end{tabular}

Inserts of size 42 and 43 were used in the tests. The thickness and length of both variants are summarized in the Table 1. The thickness of the inserts did not depend on the size and was $3.53 \mathrm{~mm}$ on the insole surface and $0.9 \mathrm{~mm}$ at the weld point, respectively.

\section{Methodology}

Insole investigations were conducted according to the following test sequence:

- tests of insoles:

- hygienic properties: absorption and desorption under dynamic conditions using acidic and alkaline artificial sweat ( $\mathrm{pH} 5$ and 8 , respectively)

- mechanical properties: tear strength.

- tests of the insole-protective footwear system using T/RH sensors:

- microclimate inside footwear in a climatic chamber,

- microclimate inside footwear on a thermal foot model,

- microclimate inside footwear on human subjects.

\subsection{Testing insoles for absorption and desorption under dynamic conditions and tear strength evaluation}

Prior to dynamic tests, the insole materials were characterized in terms of moisture vapor transmission and sorption dynamics using a SORP 3 sorption meter [19] (Table 2).

Subsequently, dynamic tests were performed to investigate water absorption and desorption pursuant to the requirements specified for protective footwear in the standard [20], with two modifications that were designed to simulate footwear use in real-life conditions:

- the application of a load (500 N) equivalent to the average weight of a person;

- the use of liquids with different $\mathrm{pH}$ levels - acidic and alkaline artificial sweat. 
Table 2. Moisture vapor transmission and sorption dynamics for the tested insole variants

\begin{tabular}{|c|c|c|c|c|}
\hline Variants & $\begin{array}{c}\text { Moisture vapor } \\
\text { transmission }(\mathrm{gm}-224 / \mathrm{T})\end{array}$ & $\begin{array}{l}\text { Maximum sorption } \\
\qquad\left(\mathrm{mL} / \mathrm{cm}^{2}\right)\end{array}$ & $\begin{array}{l}\text { Maximum sorption rate } \\
\qquad\left(\mathrm{mL} / \mathrm{cm}^{2} \mathrm{~s}\right)\end{array}$ & Sorption capacity $(g / g)$ \\
\hline I & 3028.5 & 316 & 6.97 & 7.0 \\
\hline II & 4039.7 & 493 & 10.2 & 13.1 \\
\hline
\end{tabular}

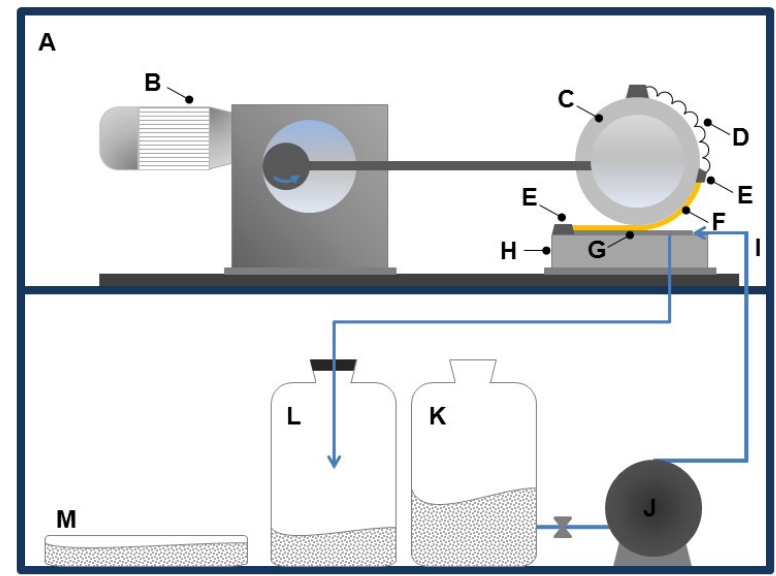

Figure 2. Setup used for dynamic insole testing: (A) climatic chamber, (B) drive, (C) brass cylinder, (D) spring, (E) clamp, (F) sample, (G) gauze dipped in artificial sweat, $(\mathrm{H})$ platform, $(\mathrm{I})$ sweat supply, $(\mathrm{J})$ pump, (K) sweat container, (L) container for excess sweat, and (M) tray with water.

Samples measuring $110 \mathrm{~mm} \times 50 \mathrm{~mm}$ were cut out from the front part of insoles and mounted in the apparatus shown in Figure 2.

The apparatus applied the set pressure to the sample on the platform and bent it in a way that is similar to insole behavior during protective footwear use. Perspiration was simulated by the supply of artificial sweat $[21,22]$. The setup was placed in a climatic chamber $(\mathrm{A})$ maintaining a temperature of $30^{\circ} \mathrm{C}$ and a relative humidity of $80 \% \mathrm{RH}$ to reflect the microclimate inside safety footwear. Prior to tests, the sample was weighed with an accuracy of $1 \mathrm{mg}\left(\mathrm{m}_{\mathrm{o}}\right)$. The sample was mounted in such a way so that the side of the insole normally facing the foot was in contact with the gauze $(G)$ covering the surface of the platform $(\mathrm{H})$. One end of the sample was attached to the platform, and the other one to the cylinder $(\mathrm{C})$, which exerted the set pressure on the sample. During tests, artificial sweat (I), either acidic $(\mathrm{pH}$ $5.5)$ or alkaline $(\mathrm{pH} 8)$, was supplied onto the platform at a rate of $5 \mathrm{~mL} / \mathrm{h}$ to imitate human perspiration under conditions of strenuous work. Each test lasted $8 \mathrm{~h}$, which equals to a work shift. At the end of the test, the sample was weighed with an accuracy of $1 \mathrm{mg}\left(\mathrm{m}_{\mathrm{F}}\right)$. Subsequently, the sample was dried under controlled conditions $\left(23^{\circ} \mathrm{C}\right.$ and $\left.50 \% \mathrm{RH}\right)$ for $24 \mathrm{~h}$, and again weighed with an accuracy of $1 \mathrm{mg}\left(\mathrm{m}_{\mathrm{R}}\right)$.

Absorption $\left(W_{A}\right)$ was calculated in $\left(\mathrm{mg} / \mathrm{cm}^{2}\right)$ from the formula:

$W_{A}=\frac{m_{F}-m_{O}}{A}$

where $m_{O}$ is -initial weight $(\mathrm{mg}), \mathrm{m}_{\mathrm{F}}$ - is final weight $(\mathrm{mg})$, and A - is sample area $\left(\mathrm{cm}^{2}\right)$.
Desorption $\left(\mathrm{W}_{\mathrm{D}}\right)$ was calculated in (\%) from the formula:

$W_{D}=\frac{m_{F}-m_{R}}{m_{F}-m_{O}} \times 100$

where $m_{\mathrm{O}}$ - is initial weight $(\mathrm{mg}), \mathrm{m}_{\mathrm{F}}$ - is final weight $(\mathrm{mg})$, and $m_{R}$ - is weight after drying (mg).

After the hygienic tests, the samples were examined for their mechanical properties, that is, tear strength [23] is applied to investigate the changes in insole structure. So, the individual layers of a $30 \times 100 \mathrm{~mm}$ sample were mounted in the clamps of a universal testing machine (Instron, USA) after $24 \mathrm{~h}$ of drying under a controlled atmosphere and pulled at a rate of $100 \pm 10 \mathrm{~mm} / \mathrm{min}$ (Figure 3). Tear strength was calculated in N/ $\mathrm{mm}$ from the formula:

$$
\text { Tear strength }=\frac{\text { Mean tearing force }[\mathrm{N}]}{\text { Sample width }[\mathrm{mm}]}
$$

Further, the microstructure of the middle layer made of a melt-blown nonwoven with functional modifiers (SAP and a biocide) was analyzed using a scanning electron microscope (FEI NOVA NanoSEM 230, The Netherlands). Samples of the middle layer were mounted on the microscope platform with a carbon tape. Images were acquired under low vacuum using secondary electron detection with an electron beam of $10 \mathrm{keV}$.

\subsection{Testing the microclimate inside the insole-footwear system in a climatic chamber}

The microclimate inside protective footwear, i.e., the conditions in the space between the foot, insole, and footwear, was measured using an integrated temperature and relative humidity $(\mathrm{T} / \mathrm{RH}$ ) sensor (iButton, USA). First, an insole and a sock were inserted into the footwear, and an activated $\mathrm{TR} / \mathrm{H}$ sensor was
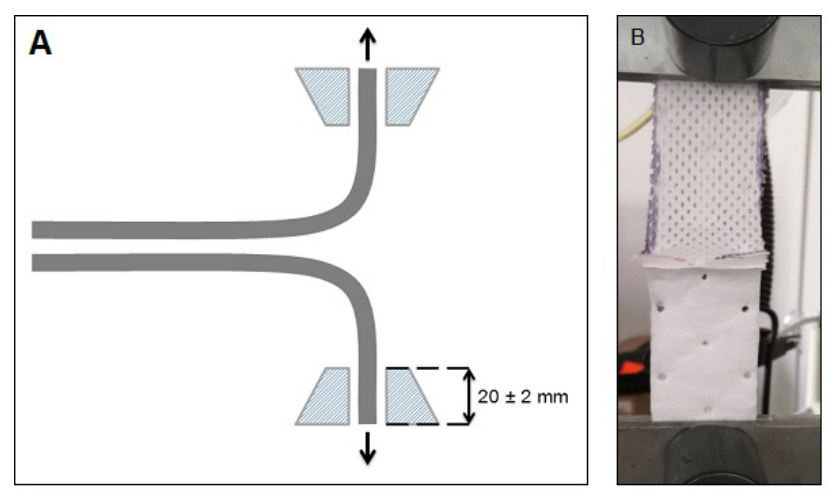

Figure 3. Insole sample mounted in the clamps of a universal testing machine. (A) diagram and $(B)$ actual view. 
fitted in the metatarsal region. The tested system was placed in a climatic chamber which maintains temperature of $30^{\circ} \mathrm{C}$ and a relative humidity of $80 \%$. Continuous measurements were conducted for $8 \mathrm{~h}$ with data points recorded every minute. The records were read at the end of the trial. It is assumed that the relative humidity inside the footwear below $80 \%$ ensures comfort for the user, while after exceeding $80 \%$, the user begins to perceive discomfort.

\subsection{Testing the microclimate inside the insole-footwear system on a thermal foot model}

The effects of insoles on the relative humidity and temperature in protective footwear were evaluated on a thermal foot model (ATT Electro, Poland). Experiments were conducted at $33^{\circ} \mathrm{C}$ for $8 \mathrm{~h}$ at a sweating rate of $10 \mathrm{~g} / \mathrm{h}$, which is characteristic of medium used for hard physical exertion. The objective was to determine relative humidity in the space between the plantar foot region and insole inside the footwear [24].

\subsection{Testing the microclimate inside the insole-footwear system on human subjects}

This part of the study involved five volunteers who were professionally active firefighters. Footwear microclimate tests were conducted on a treadmill set to a speed of $5 \mathrm{~km} / \mathrm{h}$ (Figure 4). Relative humidity and temperature in the plantar foot region were measured with an accuracy of $\pm 1.5 \%$ using an integrated $\mathrm{T} / \mathrm{RH}$ sensor positioned between the insole and sock, under the longitudinal arch of the foot. Temperature and relative humidity were measured on continuously, with readings taken at every $60 \mathrm{~s}$. The tests were conducted in a laboratory at constant climatic conditions: an air temperature of $23 \pm 2^{\circ} \mathrm{C}$, a relative humidity of $50 \pm 5 \%$, and an air flow of $0.10 \mathrm{~m} / \mathrm{s}[25,26]$. This test consisted of three phases: phase I -10 min of rest; phase $\mathrm{II}$ - walking on the treadmill for $60 \mathrm{~min}$; and phase III - $30 \mathrm{~min}$ of rest.

\subsection{Statistical analysis of results}

Statistical analysis was performed using Statistica ver. 13.1 software. Statistical significance was evaluated using oneway analysis of variance (ANOVA). Differences between insole variants were assessed by means of Tukey's test at a significance level of $p \leq 0.05$. Results were given as means \pm standard deviation (SD).

\section{Results and discussion}

\subsection{Results of tests for absorption and desorption under dynamic conditions and tear strength evaluation}

The results of insole tests for liquid absorption and desorption under dynamic conditions are given in Table 3.

Both insole variants met the standard requirements, that is, absorption of $70 \mathrm{mg} / \mathrm{cm}^{2}$ and $80 \%$ desorption. Variant II samples exhibited higher absorption of alkaline sweat characteristic under strenuous exertion (134.62-155.22 mg/ $\mathrm{cm}^{2}$ at $\mathrm{pH} 8$ ) as compared to acidic sweat reflecting skin $\mathrm{pH}$ (133.22-152.13 mg/cm ${ }^{2}$ at $\mathrm{pH}$ 5). The absorption values obtained for variant I samples were lower by approximately $55-64 \%$ for alkaline sweat and by $30-33 \%$ for acidic sweat. But, desorption was close to $100 \%$ irrespective of insole variant and sweat $\mathrm{pH}$.

Statistical analysis of absorption results revealed significant differences between insole variants, but not between different sweat $\mathrm{pH}$ values. No statistically significant differences were observed in the case of desorption results.

Further, scanning electron microscopy was employed to qualitatively evaluate morphological changes in the microstructure of insole samples after the liquid absorption and desorption studies. Figure 5 presents examples of SEM images of samples before and after tests at a magnification of 10,000x, which makes it possible to observe SAP and biocide particles deposited on the surface of polypropylene fibers. As it is seen, modifier particles became redistributed or coagulated (especially in the case of the biocide) in some areas, and their overall quantity slightly decreased. However, it should be noted that no strictly quantitative analysis was possible but the recorded SEM images testify the stability of the bonding of additives to the nonwoven structure, which is important for the development of an innovative product. Importantly, the

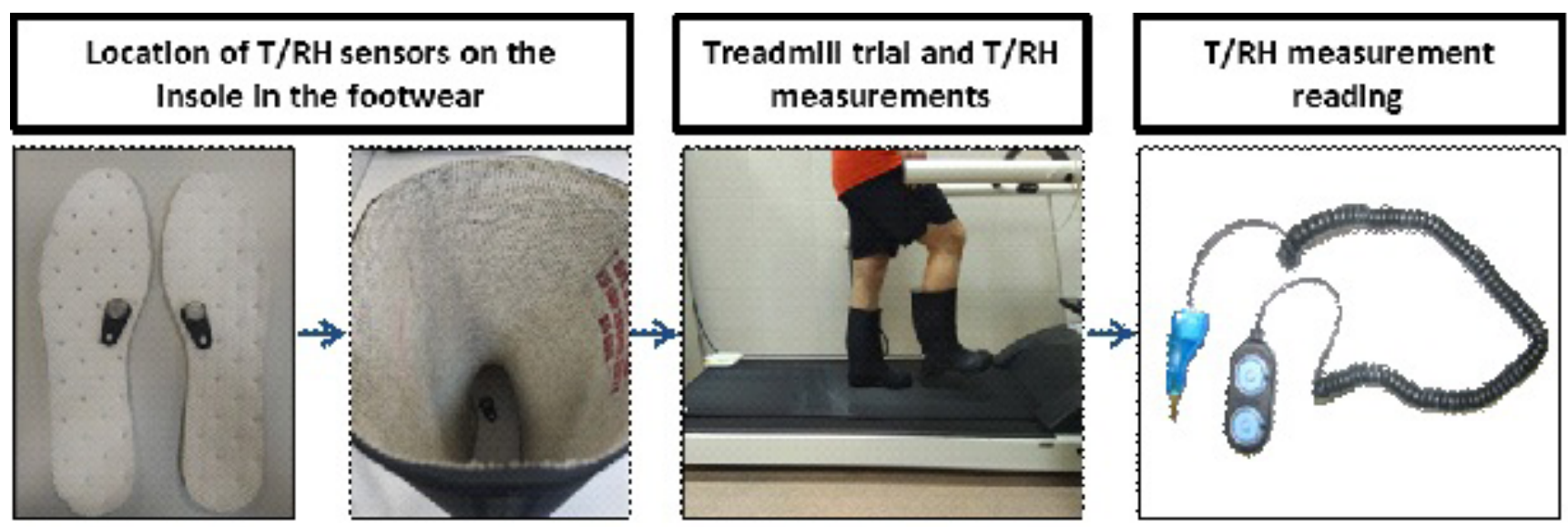

Figure 4. Study protocol for testing footwear microclimate on human subjects. 
Table 3. Insole tests for liquid absorption and desorption under dynamic conditions

\begin{tabular}{|c|c|c|c|}
\hline Variants & $\mathbf{p H}$ & Mean absorption \pm standard deviation $\left(\mathbf{m g} / \mathbf{c m}^{2}\right)$ & Mean desorption $\mathbf{s}$ standard deviation (\%) \\
\hline \multirow{2}{*}{ I } & 8 & $88.18 \pm 0.06 \mathrm{a}$ & $102 \pm 2.0 \#$ \\
\cline { 2 - 4 } & 5 & $104.47 \pm 2.37 \mathrm{a}$ & $98 \pm 0.2 \#$ \\
\hline \multirow{3}{*}{ II } & 8 & $146.05 \pm 10.48 \mathrm{~b}$ & $99 \pm 1.0 \#$ \\
\cline { 2 - 4 } & 5 & $145.64 \pm 10.76 \mathrm{~b}$ & $98 \pm 0.6 \#$ \\
\hline
\end{tabular}

Notes: Data marked with the same letters or symbols are not significantly different from each other at $p \leq 0.05$ (Tukey's test).
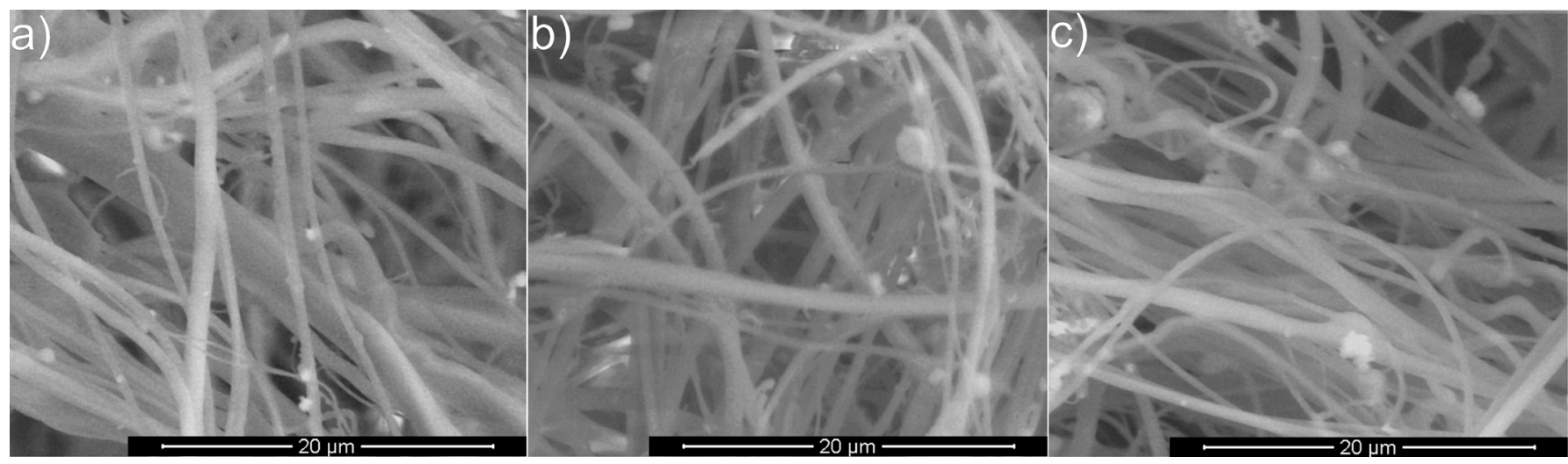

Figure 5. SEM images of the melt-blown nonwoven layer with modifiers before test (A) and after test involving acidic sweat (B), and alkaline sweat (C).

nonwoven structure (e.g., fiber diameter and orientation) did also not reveal any major alterations, which is crucial in terms of the practical use of hygienic footwear insoles.

Table 4 presents the results of tear strength tests that reflect the bonding strength between the three ultrasonically spotwelded layers. This parameter is important as it indicates the durability of insoles under practical conditions (Table 4).

As it is observed from Table 4 , the value $0.4 \mathrm{~N} / \mathrm{mm}$ does not exceed the threshold value specified in the standard in the case of both variants.

\subsection{Results of microclimate tests of the insole-footwear system in a climatic chamber}

Microclimate test results (temperature and relative humidity) for insole variant I containing an unmodified polypropylene melt-blown nonwoven and variant II with a modified nonwoven were compared and presented in Figures 6 and 7.

Table 4. Tear strength results for the studied insoles

\begin{tabular}{|c|c|c|}
\hline Variants & $\mathbf{p H}$ & $\begin{array}{c}\text { Mean tear strength } \pm \text { standard } \\
\text { deviation }(\mathrm{N} / \mathrm{mm})\end{array}$ \\
\hline \multirow{2}{*}{$\mathrm{I}$} & 8 & $0.17 \pm 0.04$ \\
\cline { 2 - 3 } & 5 & $0.26 \pm 0.12$ \\
\hline \multirow{2}{*}{$\mathrm{II}$} & 8 & $0.14 \pm 0.01$ \\
\cline { 2 - 3 } & 5 & $0.14 \pm 0.01$ \\
\hline
\end{tabular}

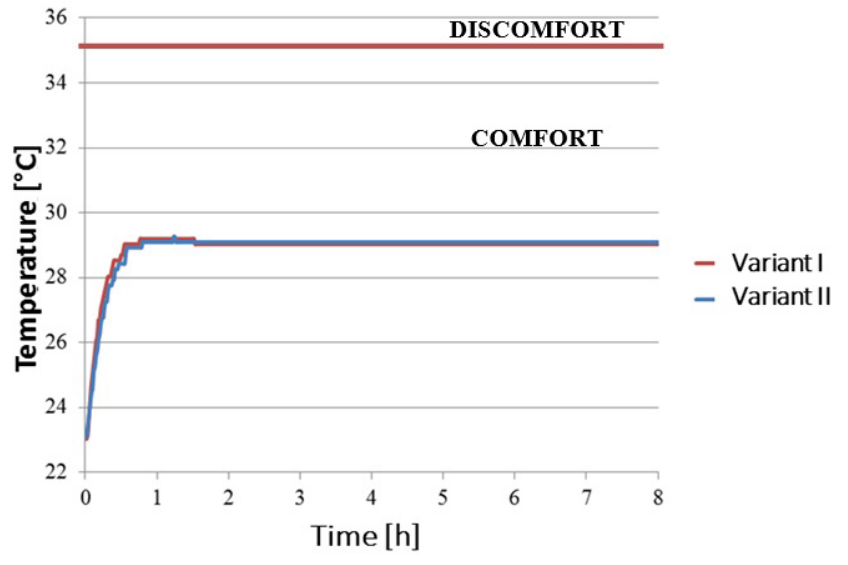

Figure 6. Temperature changes recorded under simulated use conditions in a climatic chamber.

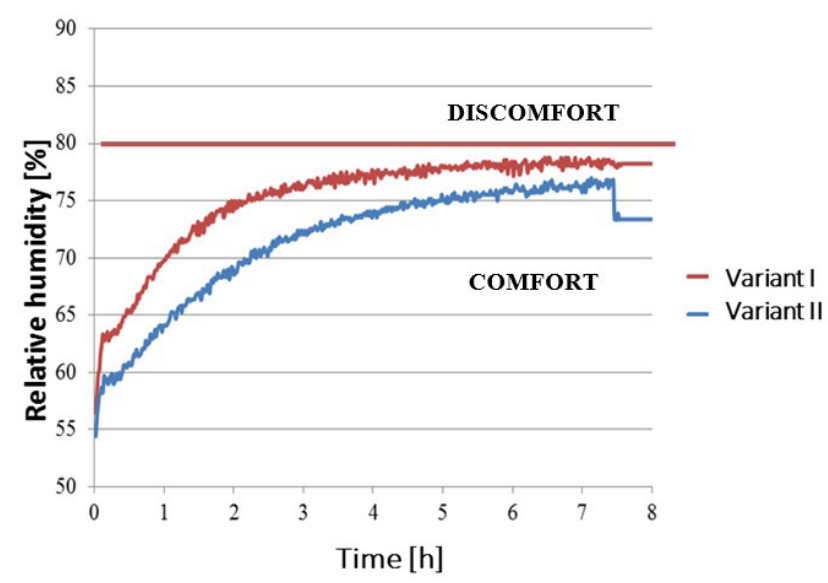

Figure 7. Relative humidity changes recorded under simulated use conditions in a climatic chamber. 
The insoles did not increase temperature inside the footwear, which reached $29^{\circ} \mathrm{C}$ for both variants that is well below the discomfort threshold of $35^{\circ} \mathrm{C}$ reported in the literature [27].

Higher relative humidity inside footwear (76-78\%) was recorded for insole variant I without modifiers as compared to variant II containing a modified melt-blown nonwoven (74-76\%). This indicates that the addition of SAP helped in absorbing moisture leading to drier conditions in the footwear. It should be noted that neither insole variant exceeded the discomfort threshold of $80 \% \mathrm{RH}$ defined in the literature [27].

\subsection{Results of microclimate tests of the insole-footwear system on a thermal foot model}

The effects of insoles on relative humidity and temperature in protective footwear were also investigated using a thermal foot model. It was observed that the type of insole affected the speed of reaching the discomfort level. Footwear with insole variants I was found to exceed the $80 \% \mathrm{RH}$ threshold after $3 \mathrm{~h}$ of use under the conditions of strenuous physical exercise (Figures 8 and 9), thus compromising user comfort. But, in variant II the level of discomfort was achieved only after $5 \mathrm{~h}$. It should be noted that the presented experiments reflected the continuous use of footwear with insoles irrespective of any rest intervals that are normally required during actual hard physical work.

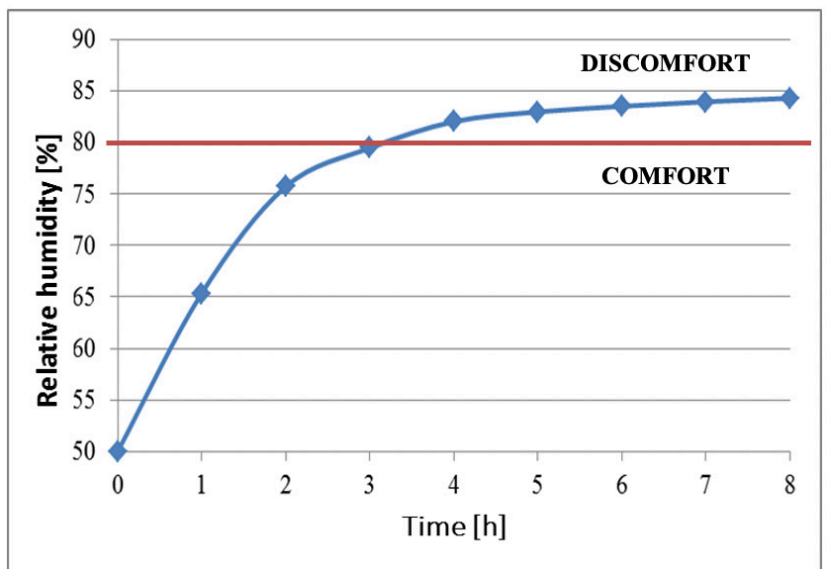

Figure 8. Changes in relative humidity inside footwear with insole variant I recorded on a thermal foot model.

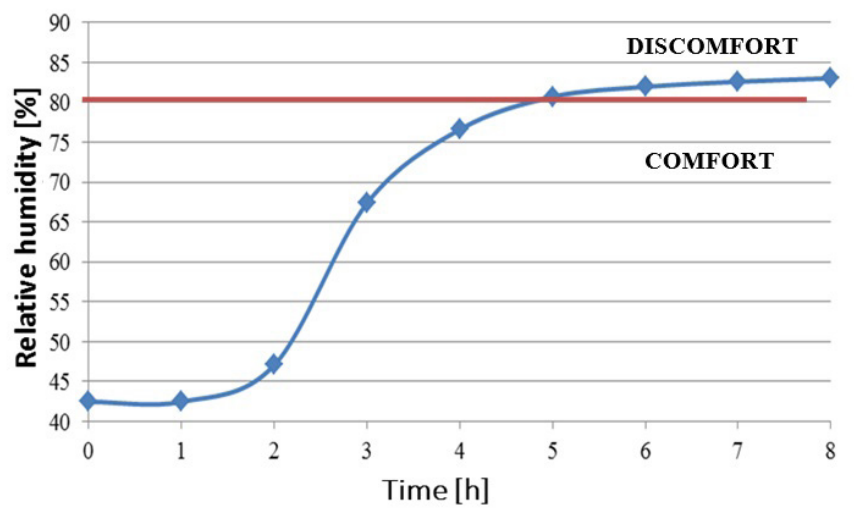

Figure 9. Changes in relative humidity inside footwear with insole variant II recorded on a thermal foot model.

\subsection{Results of microclimate tests of the insole-footwear system on human subjects}

The results obtained from tests on human subjects show that the discomfort threshold for temperature $\left(35^{\circ} \mathrm{C}\right)$ was not exceeded in most cases irrespective of insole variant, indicating comfortable conditions during strenuous physical work (Figure 10). However, the application of SAP in variant II decreased temperature by $2-3^{\circ} \mathrm{C}$, which suggests superior ventilation in that insole variant. In the case of two out of five volunteers, relative humidity also remained below the discomfort threshold of $80 \%$ (Figure 11). The relative humidity recorded for the remaining users was $85-95 \%$, which may be attributable to individual physiological traits. Notwithstanding the above, the insoles with an unmodified middle nonwoven layer did not ensure sufficient sweat absorption from the skin, resulting in $82-100 \%$ RH for all participants.

\section{Summary and conclusions}

Protective footwear should be designed in such a way to avoid any adverse effects on the user's hygienic comfort and to facilitate the transport of heat and moisture away from the foot. In this context, it may be expedient to apply insoles with confirmed protective and functional properties. The methodology described in this paper enables reliable verification of insole effectiveness under dynamic conditions of simulated use.

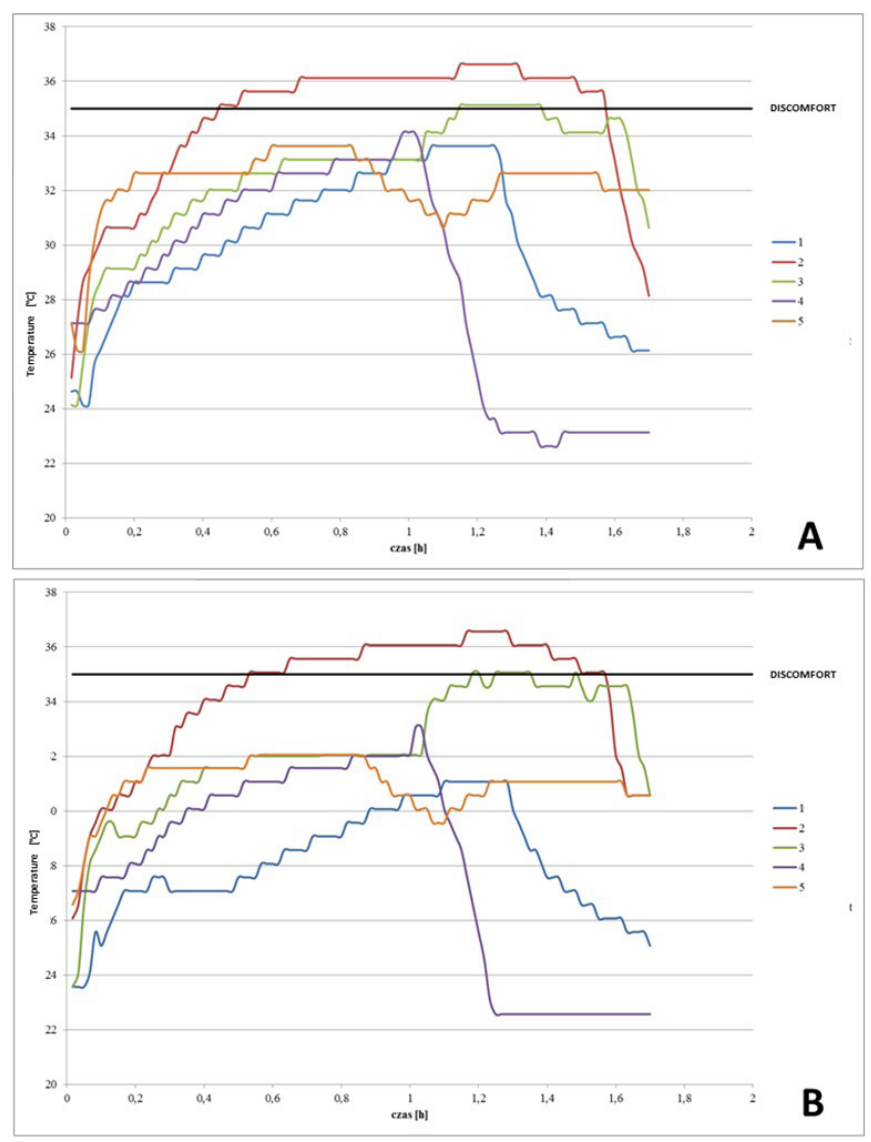

Figure 10. Insole tests involving human subjects: temperature changes over time for variant I (A) and variant II (B). 


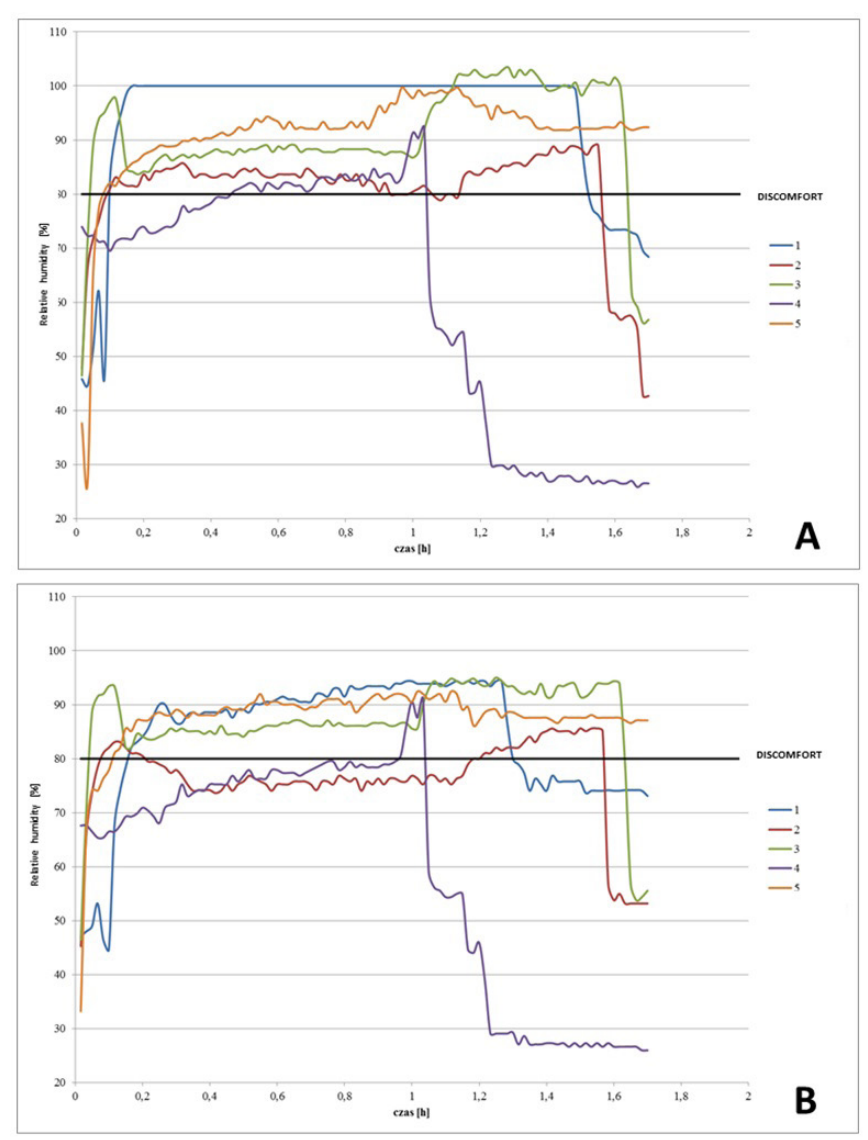

Figure 11. Insole tests involving human subjects: relative humidity changes over time for variant I (A) and variant II (B).

Literature reports have shown that sweat with different $\mathrm{pH}$ levels should be used for determining the sorptive properties of linings, inserts, and insoles in the hygienic evaluation of protective footwear [13]. Thus, the present study used both acidic and alkaline artificial sweat (with $\mathrm{pH} 5$ and 8 , respectively) to simulate real-life footwear conditions. This is important as during intensive exertion alkaline sweat with a high concentration of organic compounds, decrease in surface tension may be less effectively distributed within the textile structure. Previous physical and chemical analyses available in the literature have dealt with the sorption kinetics of acidic and alkaline sweat associated with absorption, surface wetting, as well as capillary transport within the pores of textile footwear materials. In the present study, the absorption of alkaline and acidic artificial sweat by unmodified insoles (as compared to insoles containing SPA and a biocide) was lower by 55-64\% and $30-33 \%$, respectively, which is consistent with other papers. In turn, desorption was close to $100 \%$ irrespective of insole variant and sweat $\mathrm{pH}$. However, statistical analysis of absorption and desorption results indicates the absence of significant differences between experiments involving acidic and alkaline sweat. This may be attributable to the application of an $80 \mathrm{~N}$ pressure to samples; further both insole variants contained high-performance nonwovens absorbing moisture from the air saturated with water vapor. These factors may have hindered moisture transport in the nonwoven structure which is reflected in weight measurements. When the results of mechanical evaluation are considered after dynamic absorption and desorption measurements, it is found that there is no substantial changes or defects in the nonwoven structure, which shows that the tested insoles exhibit stable functional properties.

The microclimate inside protective footwear with insoles was measured using three complementary methods providing a comprehensive evaluation of insole effectiveness. One method involved the measurement of temperature and relative humidity inside footwear under controlled climatic conditions using $\mathrm{T} / \mathrm{RH}$ sensors ("in vitro" experiments). It was found that the insoles did not significantly affect temperature in the footwear, with $29^{\circ} \mathrm{C}$ recorded for both insole variants, which is well below the discomfort threshold of $35^{\circ} \mathrm{C}$ [27]. In addition, higher relative humidity $(76-78 \%)$ was observed for insoles without modifiers (variant I) as compared to insoles with modifiers (74-76\%), which indicates that SAP effectively removes moisture from the footwear microclimate. In both cases relative humidity levels remained below $80 \%$, which suggests user comfort.

The second "in vitro" method of testing the transport of heat and moisture inside protective footwear with insoles involved a thermal foot model. The results show that the discomfort threshold of $80 \% \mathrm{RH}$ was exceeded for both insole variants after $3 \mathrm{~h}$ of simulated intensive physical exertion. However, it should be noted that the continuous experiments did not reflect the rest intervals normally required during real-life work, where humidity levels will be less. Further, relative humidity dynamics differed between the two insole variants. It is observed that the relative humidity increased rapidly and exceeded the discomfort threshold after $3 \mathrm{~h}$ of simulation for variant I, while in footwear with insole variant II (with SAP) relative humidity remained below $45 \%$ for almost $2 \mathrm{~h}$, and the discomfort threshold was exceeded only after $5 \mathrm{~h}$.

Finally, heat and moisture transport within protective footwear with insoles was also studied using an "in vivo" method involving human subjects. The objective was to assess the subjective sensations of users by determining microclimate changes when walking on a treadmill. While experiments with different volunteers are difficult to interpret due to individual differences between participants, it should be noted that the application of a SAP-containing nonwoven in insoles decreased the temperature inside the footwear by $2-3^{\circ} \mathrm{C}$, which suggests better ventilation. In the case of two out of five volunteers, relative humidity remained below the discomfort threshold of $80 \%$. The humidity values recorded for the remaining participants ranged from $85 \%$ to $95 \%$. However, the value does not necessarily indicate an inferior performance of the tested insoles with SAP, as the differences could also be attributable to the individual physiological traits of the volunteers. Apart from the above, it is found that the insoles without SAP failed to effectively remove sweat from the skin, resulting in $82-100 \%$ $\mathrm{RH}$ values for all participants.

The microclimate results obtained in this study are presented in the form of temperature and relative humidity curves reflecting changes in those parameters over time. The plots can be used to identify those insole designs that have beneficial effects on the microclimate inside protective footwear with insoles during use. It should be remembered that according to literature 
data, the optimum relative humidity inside protective footwear should be in the range of $60-80 \%$. It has been reported that the temperature range of human feet should be between $20^{\circ} \mathrm{C}$ and $33^{\circ} \mathrm{C}$ for comfort zone $[1,14]$, with temperatures between $35^{\circ} \mathrm{C}$ and $38^{\circ} \mathrm{C}$ being regarded as uncomfortable $[1,13]$.

The results of all tests clearly show that insoles with a SAPmodified nonwoven are more effective than those without SAP. It was found that the improved moisture sorption properties of SAP-containing insoles resulted in decreased relative humidity levels inside protective footwear, which emphasizes the role of insole materials with high water sorption capacity.

In addition, the presented research methodology enables a comprehensive perspective on testing insoles for protective footwear with elements of objective and subjective evaluation. The obtained results reveal the following relationships between the properties of the developed textile structures and the hygienic and mechanical factors affecting the comfort of protective footwear users:

- Absorption and desorption tests of insoles under dynamic conditions show that the presence of SAP imparts very good sorption properties effectively improving the distribution of alkaline sweat, which is typically secreted during hard physical work, while mechanical experiments and SEM observations indicate a high functional durability of the tested insoles.

- Microclimate tests of the insole-footwear system, conducted using both "in vivo" and "in vitro" methods, indicate that SAPcontaining insoles absorb moisture from the air much more effectively than insoles without SAP, and can successfully reduce relative humidity levels inside protective footwear.

\section{ACKNOWLEDGMENTS}

The work is based on the results of the Tech-Kom project: 'Technology for the production of multifunctional composites for human protection in heavy working conditions' funded in the years $2015-2018$ by the National Centre for Research and Development (project consortium: CIOP-PIB, Łódź University of Technology, Maskpol S.A.). The authors would like to thank the protective equipment company Maskpol S.A. for help in the spot-welding of the composite materials studied in the present paper.

\section{References}

[1] Akbar-Khanzadeh, F., Bisesi, M. S., Rivas, R. D. (1995). Comfort of personal protective equipment. Applied Ergonomics, 26(3), 195-198. doi: 10.1016/00036870(95)00017-7.

[2] Hole, L. G. (1973). Sweat disposal from footwear and health and hygiene of foot skin. Journal of the Society of Cosmetic Chemists, 24, 43-63.

[3] Regulation (EU) 2016/425 of the European Paliament and of the council of 9 March 2016 on personal protective equipment and repealing Council Directive 89/686/EEC. 2016.
[4] Europejska strategia rozwoju do 2020 r. pt.: Long Term Personal Protective Equipment Perspective of the European Union'. Jun. 07, 2020, [Online]. Web site: https:// ec.europa.eu/growth/sectors/mechanical-engineering/ personal-protective-equipment_en.

[5] Guidance for the selection, use and maintenance of safety and occupational footwear and other personal protective equipment offering foot and leg protection. Technical Committee.

[6] Scheffer, M. (2012). Long term PPE perspective. HSME Magazine Health \& Safety Middle East., 19, 25-33.

[7] Holmer, I. (2004). Thermal manikin history and applications. European Journal of Applied Physiology, 92(6), 614-618. doi: 10.1007/s00421-004-1135-0.

[8] Kuklane, K., Holmér, I., Anttonen, H., Burke, R., Doughty, $P$. (2005). Inter-laboratory tests on thermal foot models. Elsevier Ergonomics Book Series, 3, 449-457.

[9] Frederick, E. C. (1984). Physiological and ergonomics factors in running shoe design. Applied Ergonomics, 15(4), 281-287. doi: 10.1016/0003-6870(84)90199-6.

[10] Irzmańska, E. (2016). The microclimate in protective fire fighter footwear: Foot temperature and air temperature and relative humidity. Autex Research Journal, 16(2), 7579. doi: 10.1515/aut-2015-0030.

[11] Irzmańska, E. (2015). The impact of different types of textile liners used in protective footwear on the subjective sensations of firefighters. Applied Ergonomics, 47, 34-42. doi: 10.1016/j.apergo.2014.08.013.

[12] Yang, Y., Hao, X. M., Hao, X., Li, H. W., Feng, X. X. (2012). Investigate on moisture absorption/desorption of shoe material containing hemp fiber. Advanced Materials Research, 627, 49-52. doi: 10.4028/www.scientific.net/ AMR.627.49.

[13] Irzmańska, E., Brochocka, A. (2014). Influence of the physical and chemical properties of composite insoles on the microclimate in protective footwear. Fibres \& Textiles in Eastern Europe, 22, 5(107), 89-95.

[14] Mitsui, M., Yoshida, K., Ishii, Y., Shirai, K., Chonan, Y., Okamura, H. (1999). Hygienic study on shoes part 1: Effect of shoe materials on wear comfort and microclimate between shoes and skin. Journal of the Japan Research Association for Textile End-Uses, 40(5), 333-341. doi: 10.11419/senshoshi1960.40.333.

[15] Gulbiniene, A., Jankauskaitè, V., Kondratas, A. (2011). Investigation of the water vapour transfer properties of textile laminates for footwear linings. Fibres \& Textiles in Eastern Europe, 19, 3(86), 78-81.

[16] Majchrzycka, K. (2017). Wykorzystanie polimerów superabsorpcyjnych w materiałach włókienniczych. Chemical Review, 1(10), 122-125. doi: 10.15199/62.2017.10.20.

[17] Irzmańska, E., Brochocka, A. (2017). Modified polymer materials for use in selected personal protective equipment products. Autex Research Journal, 17(1), 35-47. doi: 10.1515/aut-2015-0040.

[18] Irzmanska, E., Majchrzycka, K., Adamus-Włodarczyk, A., Brochocka, A. (2019). Evaluation of the mechanical parameters of ultrasonically welded textile composite structures for protective footwear. Fibres \& Textiles in Eastern Europe, 27, 3(135), 99-105. doi: 10.5604/01.3001.0013.0821. 
[19]PN-EN 13726-2:2005 Metody badania bezpośrednich opatrunków ran -Część 2: Transmisja pary wilgoci przez opatrunki z folią półprzepuszczalną.

[20]EN ISO 20345:2011 Personal Protective Equipment safety footwear. 2011.

[21] PN-EN ISO 105-E04:2011 (Tekstylia. Badania odporności wybarwień. Część E04: Odporność wybarwień na działanie potu)'.

[22] Petrulyte, S., Baltakyte, R. (2009). Liquid sorption and transport in woven structures. Fibres \& Textiles in Eastern Europe, 17, 2(73), 39-45.

[23] PN-EN 1392:2007 Kleje do skóry i materiałów obuwniczych -Kleje rozpuszczalnikowe $i$ dyspersyjne -Badanie wytrzymałości połączenia w określonych warunkach.
[24] Irzmańska, E. (2014). Case study of the impact of toecap type on the microclimate in protective footwear. International Journal of Industrial Ergonomics, 44(5), 706714. doi: 10.1016/j.ergon.2014.07.006.

[25] PN-EN ISO 20344:2012 - Środki ochrony indywidualnej Metody badania obuwia.

[26] Bogusławska-Bączek, M., Hes, L. (2013). Effective water vapour permeability of wet wool fabric and blended fabrics. Fibres \& Textiles in Eastern Europe, 1(97), 67-71.

[27] Adomaviciene, M., Schwartz, A., Stanys, S. (2013). Influence of liquid nature on wetting behaviour of an inclined fibre. Fibres \& Textiles in Eastern Europe, 15, 5(6), 67-71. 